\title{
Modelos cognitivos en las representaciones sociales para la baja autoestima y la ingesta de alcohol en canciones de la sierra peruana
}

\author{
Cognitive models in social representations for low self-esteem and alcohol drinking in lyrics \\ of peruvian andean songs
}

Antonieta del Pilar Uriol Alva' (iD (8) , Fredy Fernando Rodríguez Canales² (i) (8)

\section{Cómo citar}

Uriol Alva, A. y Rodríguez, F. (2021). Modelos cognitivos en las representaciones sociales para la baja autoestima y la ingesta de alcohol en canciones de la sierra peruana. Socialium, 5(2), 99-119. https://doi.org/10.26490/uncp.sl.2021.5.2.943

${ }^{1}$ Doctora en Ciencias de la Educación,

Psicóloga y Licenciada en Educación.

Universidad Nacional de Huancavelica,

Huancavelica, Perú.

antonieta.uriol@unh.edu.pe

2 Doctor en Psicología, Psicólogo y Licenciado en Educación. Universidad Nacional de Huancavelica, Huancavelica, Perú. fredy.rodriguez@unh.edu.pe

Arbitrado por pares ciegos

Recibido: $16 / 05 / 2021$

Aceptado: $28 / 06 / 2021$

\section{RESUMEN}

El objetivo fue identificar y analizar los modelos cognitivos de predominio que sustentan las representaciones sociales para la baja autoestima y la ingesta de alcohol en las canciones de la sierra peruana, en una investigación básica de nivel descriptivo, con enfoque cualitativo y diseño fenomenológico. La muestra lo conforma una antología de 100 canciones de la sierra peruana, siendo el criterio de inclusión que sus contenidos hagan alusión al alcohol y/o la baja autoestima. Como base teórica para el análisis de contenido de los modelos cognitivos se abordó desde la perspectiva del paradigma cognitivo-conductual que sustentan las representaciones sociales. Los resultados se analizan en una articulación teórica de dos paradigmas del campo de la psicología; las representaciones sociales de Jodelet, así mismo los modelos cognitivos del enfoque racional emotivo de Beck y Ellis. Se identifican y analizan 18 modelos cognitivos y se concluye que las canciones, cuyos contenidos aluden al alcohol, la baja autoestima o ambas, expresan dos o más formas de modelos cognitivos que orientan a reacciones conductuales y emocionales, como: culpar y evadir responsabilidad, inutilidad, impotencia, fragilidad y desamparo, pensamientos y/o sentimientos dicotómicos, esperanza en lo extrahumano, victimización, autoculpa y merecimiento, absolutismo del todo o nada, evocación del pasado; evasión, abandono e ideación suicida, necesidad absoluta de afecto y compañía, susceptibilidad a la estafa y la traición, fijación en lo negativo, anticipación de los resultados, absolutismo del siempre o nunca, miedo a lo desconocido, magnificación o catastrofización, salto a las conclusiones y descalificación de lo positivo.

Palabras clave: pensamiento; percepción social; alcoholismo; autoestima; baja autoestima.

\section{ABSTRACT}

The objective was to identify and analyze the cognitive models of predominance that support the social representations for low self-esteem and alcohol intake in the songs of the Peruvian highlands, in a basic, documentary, descriptive and explanatory research, with hermeneutic method. The sample consists of an anthology of 100 songs from the Peruvian highlands, being the inclusion criterion that its contents allude to alcohol and / or low self-esteem. As a theoretical basis for the content analysis of cognitive models was approached from the perspective of the cognitive-behavioral paradigm that support social representations. The results are analyzed in a theoretical articulation of two paradigms in the field of psychology; thesocial representations of Jodelet, as well as the cognitive models of the emotive rational approach of Beck and Ellis. We identify and analyze 18 cognitive models and conclude that thesongs, whose contents allude to alcohol, low self-esteem orboth, express two or more forms of cognitive models that guide behavioral and emotional reactions, such as: guilt and evade responsibility, uselessness, impowerence, fragility and helplessness, dichotomous thoughts and / or feelings, hope in the extrahuman, victimization, self-blame and deservedness, absolutism of all or nothing, evocation of the past; evasion, abandonment and suicidal ideation, absolute need for affection and companionship, susceptibility to fraud and betrayal, fixation on the negative, anticipation of results, absolutism of the always or never, fear of the unknown, magnification or catastrophization, jump to conclusions and disqualification of the positive.

Keywords: thinking; social perception; alcoholism; self-esteem; low self-esteem. 


\section{Introducción}

En la sociedad peruana, como en muchos países de Latinoamérica, hay una tendencia a abordar los problemas sociales y de desarrollo humano desde una perspectiva sesgada a lo financiero de inversión económica, sin tomar en cuenta la necesidad de un cambio en la subjetividad y los patrones psicosociales presentes en las personas como condicionantes fundamentales que garanticen el bienestar, como el acceso a servicios básicos con equidad, atención de salud, educación de calidad, seguridad social, vivienda, seguridad ciudadana, acceso a la justicia, empleo digno, bienes culturales y esparcimiento saludable, como ponen de manifiesto el Ministerio de Educación y el Consejo Nacional de Educación (2007) en el Proyecto Educativo Nacional al 2021, donde además plantean que, para asegurar la calidad de la educación, sea formal e informal se debe actuar sobre diversas dimensiones del tejido institucional y social del país. Evidencia esta discordancia, por ejemplo, que el Perú es uno de los países latinoamericanos donde el gasto público en educación en el año 2018 fue del 3,7 \% del PBI, muy por debajo de países como Bolivia con el 6,5 \% y Brasil con el 6,1 \% (Perú21, 2017).

Es importante añadir que, para garantizar el bienestar personal y social, se debe también intervenir en la formación ético-moral, en los valores, habilidades sociales, estilos de vida y actitudes de sentido trascendente, considerando que estos fenómenos están ligados al aprendizaje social del comportamiento humano.

Algunas expresiones de orden socio cultural, como sucede con algunas canciones de la sierra peruana, por los contenidos de las letras, estarían afectando las potencialidades de un importante sector de la población peruana, por lo que amerita analizarlas desde una mirada de las ciencias sociales y la psicología los mensajes que en ellos se difunden, siendo necesario por tanto, entender los aspectos de orden afectivo, emocionales y de sustento cognitivos, y a partir de ello poder contar con criterios que viabilicen estrategias orientadas a promover una vida saludable sobre la base de un lenguaje alternativo de sentido más positivo y de promoción del fortalecimiento de capacidades en las personas para gestionar su bienestar y desarrollo.

Analizar los modelos cognitivos en las representaciones asociados a la baja autoestima y la ingesta de alcohol declaradas en parte del cancionero de la sierra peruana en el marco de los postulados sobre las representaciones sociales de Jodelet (1993), es de trascendental importancia, ya que aborda un aspecto relacionado con la subjetividad de los pobladores de la sierra peruana, en la perspectiva de aproximarnos a entender su problemática y sus carencias en tanto, no son sólo de carácter económico, sino también sociocultural y psicosocial. 
Se define la autoestima como una dimensión del mundo afectivo de las personas en cuanto sentimientos para consigo mismo y cómo a partir de ello, se proyectan en su interrelación con los demás, con el entorno y sus perspectivas en los roles a cumplir en la vida social, por lo tanto, una baja autoestima implicará sentimientos de auto subvaloración personal en primacía de un concepto de sí negativo, haciéndolos propenso al fracaso en sus proyectos o expectativas de vida lo que conlleva a la frustración e insatisfacción como elementos constantes en su subjetividad (Rodríguez, 2020).

En las manifestaciones culturales, que en parte definen una identidad social, se advierten aspectos merecedores de toda forma de valoración y difusión, por ser elementos protectores y de fortaleza para el desarrollo social de los pueblos; pero hay también expresiones de riesgo que revelan debilidad, en tanto sus contenidos inducen en un sentido de elogio a la irresponsabilidad, la desesperanza o la negligencia que es muy probable, al ser interiorizados y colectivizados como cognición social, cumplen un rol de desventaja para un afronte en actitud constructiva y positiva de las necesidades y demandas propias de estos pueblos, que muchas veces son tildados como los más pobres.

Entre algunos antecedentes de estudios relacionados a esta temática, podemos referir a los siguientes: Pardo (2018) en la Universidad Distrital Francisco José de Caldas de Bogotá, en una investigación descriptiva, con énfasis en procesos cualitativos, analizó el rol del arte, en especial del canto como mediador del proceso transformador, en el sentido que los mensajes así lo favorezcan. Como parte de la música y expresión artística del ser humano, tiene la posibilidad de influenciar en la conciencia, el carácter y la vida sensible de los individuos. Entre sus hallazgos se mencionan: el canto tiene la facultad de fortalecer la identidad de quienes la experimenten, favorece los procesos de reconocimiento y autoconocimiento al interior de una comunidad, proporcionando la posibilidad a las personas de crear nuevas formas de relación con su yo interno y con los demás, también aumentan las capacidades o habilidades existentes o escondidas. El canto, como forma de lenguaje, propicia a que se evoquen, transformen y fortalezcan emociones, generando grupos o comunidades unidos por vínculos desarrollados a partir de las vivencias.

Desde una perspectiva psicoterapéutica, Cabrera (2012) en la Universidad de San Carlos de Guatemala, en un estudio cualitativo acerca del canto como herramienta terapéutica en la mejora de la salud emocional de la mujer, con una muestra de 10 mujeres de 18 a 70 años de edad, de clase socioeconómica baja y media, solteras, separadas y casadas; con educación primaria, media y profesionales, de creencias religiosas diversas, en base a técnicas de observación, entrevistas semiestructuradas a profundidad, con estudio socio demográfico y de testimonios, desarrolló talleres durante tres meses, en base al canto como herramienta para favorecer la salud emocional de las mujeres participantes y generar procesos conducentes al bienestar físico, psíquico y social. Concluyó que el beneficio alcanzado radica en que las 
participantes lograron interiorizar su necesidad de autocuidado, manejo de sus emociones, dar a los otros lo que realmente merecen, valorar su vida y reestructurar su percepción acerca de relaciones sanas, instaurando así nuevas bases para la reconstrucción de su identidad y la posibilidad de extenderla a otras generaciones que lo necesiten.

Graham y Welch (2004), en Tucuman Argentina en un artículo sobre "El canto como un modo de comunicación", refiere que los elementos musicales básicos de la comunicación humana, expresadas en el canto, integran las emociones con la percepción y la cognición en un proceso de generación de una red de comportamientos emocionales, que son la base de la comunicación humana, además; permiten transmitir significados más complejos y de valores estéticos o la pertenencia a determinado grupo, desde la infancia hasta la edad adulta.

Lara (2004) en México, entre los resultados de un estudio sobre las representaciones sociales en la lírica de los narcocorridos como manifestación musical, destaca como núcleo central, una imagen de institución negativa del gobierno mexicano, haciendo objetiva la cotidiana realidad de la población donde se dejan ver temas y vicios añejos en la sociedad mexicana, como la corrupción, la inoperancia de las autoridades y los vínculos de los representantes de gobierno con el narco.

En el Perú, donde igualmente los estudios en esta perspectiva son escasos, por aproximación a la naturaleza del asunto de análisis, podemos mencionar los siguientes:

Zapata (1968) publica el libro Psicoanálisis del vals peruano, que significa la apertura hacia nuevas opciones y campos de investigación clínico-psicoanalítico, ante la necesidad de convalidar la problemática psicológica apreciada en las canciones; así como una aproximación sociológica y antropológica de los grupos humanos que cantan el vals como aporte a un mayor conocimiento y entendimiento de la personalidad básica del hombre peruano. En este libro se remueve "el alma popular" que se visibiliza en las melancólicas estrofas del vals, entendiendo que todo el folclor es también expresión psicodinámica popular que no solo debe ser visto como manifestación artística, sino como expresión de los sentimientos genuinos de un pueblo.

Stein (1982) en un estudio sobre el vals criollo y los valores de las clases trabajadoras de Lima reconoce a este género musical como el medio de expresión de la cosmovisión de sus compositores proletarios y hacen evidente la resignación, fatalismo, respeto a las jerarquías y la dependencia en el sistema de valores de las masas urbanas. El vals criollo, para la sociedad pobre de Lima, representa, a través de sus letras, la expresión musical que devela el sentir de la población y la sensibilidad colectiva de todo un grupo social. Montoya (1987) en su tesis doctoral en Antropología, titulada Canción quechua, historia y región en las provincias altas del sur andino, contextualizado en los departamentos de Cuzco, Apurímac, Ayacucho, 
Arequipa y Puno, advierte que, a través del análisis de contenido de la canción quechua es posible aproximarse a distinguir la realidad social de los pueblos andinos del Perú.

Hurtado (1995) saca a luz el libro, Chicha Peruana, basada en los resultados de una investigación de análisis socio musical de 937 canciones de este género de la producción del período de 1972 a 1990, que representó el $25 \%$ de la producción nacional chichera de esta época; incluye una antología de 202 canciones organizadas de acuerdo a los resultados del análisis de contenido en seis grupos temáticos: las raíces andinas, el trabajo, el tema amoroso, machismo y alcohol, la religión y el humor, y lo sociopolítico. Considera que este género musical que conjuga el sentimiento y sentido musical del huayno personifica a la subcultura andina del Perú en cuyas expresiones predominan los sentimientos de sumisión, miseria, la conexión con la delincuencia, la situación de los menores, huérfanos y/o migrantes, la resistencia, la protesta y la búsqueda de la liberación. Además, afirma que este género musical va alcanzando cada vez mayor reconocimiento y presencia en el sector poblacional de los migrantes de origen andino en la cultura urbana ya que, por medio de estas canciones se van divulgando ciertos valores de la mentalidad andina y popular, como la solidaridad y la aspiración de un sector poblacional marginado a un nuevo sistema social más justo, y son las canciones el medio de expresión del alma, identidad y condición de un pueblo.

\section{Método}

Tipo de estudio. Es básica, en un nivel descriptivo (Tamayo y Tamayo, 2009) ya que, buscó identificar y analizar los modelos cognitivos ante la baja autoestima y la ingesta de alcohol, subyacentes en las canciones de la región de la sierra peruana. Corresponde a una Investigación cualitativa en el diseño fenomenológico (Álvarez, 2003) en tanto analiza el significado de los mensajes de una antología del cancionero de la sierra peruana.

Población y muestra. Los documentos de estudio lo conformaron 500 canciones de la serranía peruana; de los cuales se definieron como objetos 100 unidades de análisis por el procedimiento de selección intencionada (Hernández y Mendoza, 2018) a cargo de un equipo de cuatro profesionales del campo social: una psicóloga, una antropóloga, un educador y una socióloga. La consideración para designar una canción como unidad de análisis fue la siguiente: que sus estrofas hagan alusión a las bebidas alcohólicas, su consumo o un sentido de baja autoestima.

Instrumento y procedimiento de recojo de datos. Para definir las categorías de análisis del contenido de las expresiones cánticas, en cuanto a los modelos cognitivos subyacentes en las canciones alusivas a la baja autoestima y la ingesta de alcohol, se solicitó el apoyo de 4 profesionales de la salud mental: dos 
psicólogos generales, un médico psiquiatra, y un psicólogo con formación en terapia cognitiva-conductual quienes, de las 100 canciones que fueron los elementos de estudio, escogieron 6 como representativas, cuyos títulos son: "Por tu culpa cervecita", "Vida bohemia", "El borracho", "En una cantina”, "Quien tomas más que yo" y "A los filos de un cuchillo" logrando identificar, a partir del análisis de estas canciones, 18 modelos cognitivos como categorías de análisis.

Tomando como base estas 18 categorías de modelos cognitivos, el mismo equipo profesional diseñó el instrumento para el registro de la información, derivada del análisis de contenido por cada uno de las 100 canciones que fueron los elementos de estudio, denominándose Formulario de Cotejo de Modelos Cognitivos en los Mensajes Cánticos (FCMCMC), que consiste en un cuadro de doble entrada. En el eje de la columna se indican las 18 categorías de modelo cognitivo y en el eje de las filas, dos recuadros; uno para el cotejo del tipo de modelo cognitivo identificado y el otro para la anotación literal del o los enunciados canticos. Finalmente, los hallazgos significativos, registrados por cada una de las 100 canciones, se consolidaron en una matriz de base de datos que fue el insumo para el análisis descriptivo.

Aspectos éticos. Al no trabajarse directamente con personas, no se puso en riesgo la integridad, perjuicio o daño hacia personas o institución alguna. En cuanto a las fuentes de información de referencia, se reconocen los derechos de propiedad intelectual de los autores, en la medida que se citan las fuentes documentarias de donde fueron recabadas, y sobre las canciones motivos de análisis, respeto a la dignidad y seguridad de los autores o cantautores, pese a ser elementos de libre acceso y masiva difusión, no se mencionan sus nombres.

El estudio, en su finalidad, objetivos y procedimientos, por intervenir en instancias intangibles o inmateriales, como son las canciones, hace que la maleficencia y la vulneración de derechos sean improbables e inexistentes, más por el contrario, será de beneficio social, en tanto la extensión de los resultados para su lectura sea un documento de libre acceso.

Análisis de datos. Por la naturaleza de investigación cualitativa documental, en base al análisis de contenido, las unidades de observación fueron las canciones seleccionadas, abordadas bajo la interpretación hermenéutico - documental; en tanto, la interpretación busca la comprensión de todo texto cuyo sentido no sea inmediatamente evidente y sea un problema interpuesto por alguna distancia (histórica, psicológica, lingüística, etc.) entre la persona y el documento. (Arráez et al., 2006) 


\section{Resultado}

La interpretación por el análisis de contenido, de las 100 canciones tamizadas, según las categorías de interpretación establecidas, permitió identificar 18 modelos cognitivos que argumentan las representaciones sobre la baja autoestima y la ingesta de alcohol; de acuerdo a la frecuencia de repetición se jerarquizan en tres niveles de predominio (alta, media y baja), como se analizan y ejemplifican a continuación:

\section{Modelos cognitivos de prevalencia alta}

Comprende el 59 \% de las canciones analizadas y son nueve los modelos cognitivos de predominio alto: culpar y evadir responsabilidad, inutilidad, impotencia, fragilidad y desamparo, sentimientos y/o pensamientos dicotómicos, esperanza en lo extrahumano, victimización, autoculpa y merecimiento, absolutismo del todo o nada, evocación del pasado y evasión, abandono e ideación suicida.

- Culpar y evadir responsabilidad, configura la tendencia a no aceptar compromisos e involucramiento frente a los acontecimientos desfavorables o negativos que a uno le puede suceder, atribuyendo responsabilidad a terceros o a situaciones ajenos a la voluntad y la autodeterminación personal. Quienes posicionen este modelo cognitivo serán incompetentes para aceptar críticas y reconocer errores o debilidades, mostrándose como personas resistentes al cambio y carentes de voluntad de corrección y superación. Expresiones que evidencian esta tendencia, recogidas en las canciones analizadas son, por ejemplo:

- “...es el culpable de mi sufrimiento, yo ya no puedo borrarlo de mi mente, es el culpable de mi sufrir" (Por qué dios mío)

- "Tu nomás tienes la culpa de todo lo que ha pasado" (Tú nomas tienes la culpa).

- "Por tu culpa cervecita he perdido a quien más amaba..." (Por tu culpa cervecita).

- "Tomo por la culpa de un amor" (Tomaré por no llorar).

- "Porque me dejaste después de quererme, eres culpable de estar borrachita" (Borrachita).

- "Amorcito por tu culpa soy bohemio, me he entregado a la bebida por tu abandono" (Por tu culpa).

- Inutilidad, comprende un conjunto de sentimientos, ideas y pensamientos en un sentido extremo negativo en la autoestima y autovaloración personal, conducentes a que las personas se consideren inservibles y que no tienen capacidad de trascendencia y de influencia positiva en su entorno. Algunos ejemplos de estas expresiones canticas son: 
Modelos cognitivos en las representaciones sociales para la baja autoestima y la ingesta de alcohol en canciones de la sierra peruana

- “...no me desprecien comprendo que ya nada valgo" (Vida bohemia).

- "Mi vida, mi alma yo le he entregado, ahora se ha alejado tal vez por ser pobre" (Oh, licor maldito).

- "Yo soy el hombre aborrecido de este lugar" (El aborrecido).

- "...huerfanito soy de padre y madre... jaya! iyay! de mí" (El huerfanito).

- "Piedra tirada en el camino ese(a) soy yo, unos irán, otros vendrán, pero ninguno me sentirá" (Piedra).

- “...soy pues como aquellas hojas que del árbol se cayó, arrastrado por el viento yo no sé dónde caer" (Soy la mala yerba).

- Impotencia, fragilidad y desamparo, está referido a sentimientos, ideas, pensamientos en un sentido de autopercepción como personas incapaces de tomar decisiones de autodefensa o emprendimiento hacia acciones que favorezca a la atención exitosa de sus necesidades y demandas en el ejercicio de sus derechos, considerándose como un ser en extrema vulnerabilidad. Algunas de las expresiones que ilustran esta forma de cognición son, por ejemplo:

- “Porque piensas olvidarme, porqué tratas de abandonarme, para mí ya no hay consuelo, para mí ya no hay alivio" (Malvacina).

- "No quiero que te olvides amorcito de mi vida, porque yo me moriría vida mía sin tu querer (Tus caricias).

- "Me desprecias porque soy pobre (Amor herido).

- "No te equivoques, quise morir, sólo era un niño; debiste ver que te amaba, pero el destino nos separó" (Sin ti no ha sido fácil).

- "iAy rosa, rosa, rosa espinosa!, esas tus espinas, hacen que me vaya, cruel destino a dónde me llevas, por el camino lleno de espinas" (Huasco* nomás).

- "Ahora se ha alejado, tal vez por ser pobre, a donde vaya ojalá encuentre riquezas y fortuna que yo no pude darle" (Oh, licor maldito).

- Sentimientos y/o pensamientos dicotómicos, es la predisposición para catalogar los objetos, circunstancias o vivencias de forma imprecisa y ambigua en dos categorías opuestas y extremas, obviando la posibilidad de estimaciones intermedias. Las personas en quienes predomina este modelo,

* HUASCO; Vocablo que en algunos pueblos del Perú significa ebrio, borracho, alcohólico. 
es de esperar, que manifiesten su indecisión o dualidad en la definición de sus sentimientos y toma de decisiones, siendo común las expresiones de entre el "querer y no querer" o "lo odio, pero lo quiero". Expresiones cánticas que revelan esta forma de modelo cognitivo, por ejemplo:

- "Esta vida bohemia poco a poquito me está matando, Oh licor maldito porque te busco si eres veneno" (Vida bohemia).

- "Entre licor y licor pronuncio tu nombre quisiera olvidarte, pero más te recuerdo" (Perdona dios mío).

- “...yo busco el olvido en tragos amargos, pero no encuentro, más bien el recuerdo pesa al infinito y me lacera" (Tragos amargos).

- “...quiero olvidar en cada vaso que yo bebo, cuanto más tomo, más y más yo te recuerdo" (Me siento herido).

- "A ti cervecita, cervecita, quiero olvidarte y ni puedo por donde voy siempre te encuentro, helada sin helar) (Cerveza más cerveza).

- "Estoy tomando perdido, borrachito en las cantinas, pensando que no vale la pena tomar ya más por ti, pero anoche estuve tomando" (Perdido en las cantinas).

- Esperanza en lo extrahumano, es cuando las personas en sus sentimientos, creencias y pensamientos atribuyen que las consecuencias o circunstancias por la que atraviesan, son consecuencia y producto del accionar de factores o fuerzas poderosas imposible de controlarlas por la capacidad personal y por tanto escapan a la voluntad de uno mismo. Son estos factores sobrehumanos los únicos capaces de reorientar el rumbo de los resultados finales. Expresiones que representan una cognición de esperanza en lo extrahumano son: "la suerte", "la voluntad divina", "el destino" "la brujería", "el maleficio", etc. Algunas expresiones canticas que ilustran este modelo cognitivo son, por ejemplo:

- “iAy borracho, borracho me llaman por mi mala suerte!” (El borracho).

- "Mi mente te nombra, mi corazón te llama, qué destino injusto de quererte tanto" (Entre licor y licor).

- "Qué será pues mi destino, dónde estará pues mi suerte, en los mares o en los ríos." (Mi suerte).

- "Solo Dios sabe por qué yo lloro, por qué padezco de esta manera, para mí pobre alma ya no hay consuelo" (Amarga suerte).

- "Somos humildes juguetes y caprichos del destino, ay justo cielo" (iAy, justo cielo!). 
- "Así habrá sido mi destino, de andar sufriendo en este mundo" (Paloma herida).

- Victimización, autoculpa y merecimiento, se da cuando las personas se involucran como responsables por ser causantes de las circunstancias por las que atraviesan; circunstancias que, generalmente, son de perjuicio, daño o sufrimiento. Bajo este modelo, los individuos expresan tendencia a autoculparse ya que ellos se consideran merecedores de tal adversidad o de lo malo que les pueda suceder. Esta óptica, en cuanto a sentimientos y forma de conceptualización, los orienta a fijarse casi de manera absoluta solo en lo negativo e interponerse barreras para reconocer bondades, cualidades e, incluso, beneficios. Algunas expresiones que reflejan este modelo cognitivo son, por ejemplo:

- "Qué sufrimiento llevo en mi vida; como castigo llevo cadenas" (Para qué quiero la vida).

- "Si el quererte fue mi perdición, si el amarte fue mi desgracia, me desprecias porque soy pobre" (Amor herido).

- "Si es que cometí un error, Dios mío, perdona, qué destino injusto el quererte tanto" (Entre licor y licor).

- “...a cada instante está en mi mente, tengo la culpa de quererte tanto/mucho" (Oh licor maldito).

- “Por qué, por qué, por qué, me enamoré de ti, nada menos que de ti (Por qué me enamoré).

- "A nadie le importa /interesa, si es por mi propia culpa para andar así/tomando (Convencido estoy).

- Absolutismo del todo o nada, enuncia una tendencia a que las conductas, sentimientos o pensamientos se expresen de manera polarizada o en extremos opuestos en cuanto a la tenencia o disfrute de aquello que a uno lo hace sentir bien o desea en la vida; no existiendo la posibilidad de situaciones intermedias. Algunas expresiones tomadas de las canciones analizadas son, por ejemplo:

- "Quiero tomar hasta embriagarme" (Me emborracho por tu amor).

- "Si esta noche me emborracho, hay palomita, no hay cantina que me aguante" (Forasterito soy).

- "Cerveza más cerveza estoy tomando yo, helada sin helar, de cualquier etiqueta cerveza debe ser" (Cerveza más cerveza).

- “De nadie quiero su compasión, dejen que llore mi soledad, y si un día vuelve a mí ignoraré que sufro por él" (Vivo tomando).

- "Así son pues las de este lugar, la chica y la grande saben engañar" (Vaso de cerveza).

- Evocación del pasado, se trata de un recuerdo persistente y reiterativa de las vivencias de especial significación para la persona; en algunos casos resultan perjudiciales en tanto obstaculizan a que la persona emprenda hacia nuevas vivencias y proyectos de mejor perspectiva. Textos líricos en esta 
orientación son, por ejemplo:

- "No quiero recordar aquel amor que me engañó, hoy quiero seguir tomando y olvidarme de su amor" (Una cerveza).

- "Quiero tomar y quiero olvidar a una linda mujer que ya no volverá, tomando una cerveza tal vez la olvidaré" (Cerveza más cerveza).

- "Hoy quiero tomar para olvidarla, pero no se puede lograr, no quiero que me hagan recordar" (Por ella).

- "Oh, licor maldito bríndame el olvido, no quiero recordar sus dulces caricias, no quiero recordar sus falsas promesas" (Oh, licor maldito).

- "Los desprecios de tus padres no olvidaré" (El aborrecido).

- "Tengo un dolor, siento un martirio, mi corazón este sangrando, por donde hay un recuerdo de los vestigios de haberte amado" (Maldita pasión).

- Evasión, abandono e ideación suicida, es la tendencia a rehusar a que se enfrenten las dificultades o transformaciones propias de la existencia, pudiendo ser desde una simple idea, retirarse, dejar las cosas a la deriva, o decisiones extremas de quitarse la vida. Es un modo de regulación cognitiva frente a las consecuencias de los eventos adversos que afronta una persona en el sentido que, es más viable evitar los problemas y responsabilidades que contraponerlas. La presencia de este modelo cognitivo se puede evidenciar, por ejemplo, a través de expresiones, como:

- "En un vaso de cerveza quisiera tomar veneno, veneno para morirme y olvidarte para siempre" (Vaso de cerveza).

- “De qué te lamentas, por qué me críticas, si así borrachita me has conocido. Tomo con mi plata y no te interesa" (Borrachita).

- "Quisiera matarme para olvidarte, porque es imposible dejar de quererte, porque es imposible, no puedo olvidarte" (Matarme quisiera).

- “Hace días que no cómo y no duermo, esta vida de bohemia que la muerte se la lleve (Mi vida ya no es vida).

- "Entregar mi vida quisiera a los filos de un cuchillo, a ver si de esa manera se acabara mi existencia" (A los filos de un cuchillo).

- "Si el engaño es humano, venga la muerte" (Llorando a mares). 


\section{Modelos cognitivos de frecuencia media}

Los modelos cognitivos presentes en un nivel de predominio medio, son tres: necesidad absoluta de afecto y compañía, susceptibilidad a la estafa y la traición y fijación en lo negativo, que alcanza al 30 \% de las canciones que aluden al alcohol y la baja autoestima. A continuación, se analizan y ejemplifican:

- Necesidad absoluta de afecto y compañía, está basada en aquella conceptualización y sentimiento de certeza que la persona, para conseguir felicidad y realización, debe contar siempre de modo imprescindible, absoluto y permanente con la compañía del ser amado y recibir de este afecto; de no ser así, no habrá bienestar y trascendencia en la existencia. Expresiones cánticas que ilustran este modelo son, por ejemplo:

- "Qué triste es la vida y amargo el trabajo, pero más amargo es vivir solito" (El borracho).

- "De qué me sirvió quererte si nunca me correspondiste, por qué he caído en desgracia" (Tu nomás tienes la culpa).

- "Qué triste había sido huaracino* separarse de un solo nido. (A los filos de un cuchillo).

- "Solo sé que por ti me muero, al no encontrar tu amor de siempre (Amor herido).

- "Sin tu amor mi vida no vale nada..., sin tu amor me estoy muriendo, vuelve cariño mío" (Tu ausencia).

- "Así será mi suerte de ser peregrino, andar de pueblo en pueblo sin ningún cariño" (Hasta siempre).

- Susceptibilidad a la estafa y la traición, cuando se es propenso a sentir, idear o pensar que la gente en el transcurso de su existencia está expuesta de manera permanente a sufrir daño por alguna maldad premeditada de parte de alguien de su entorno. Se observa que somos susceptibles de ser víctimas de la envidia y el odio constantes del que nadie está libre. La desconfianza, la duda y la sospecha son sentimientos inseparables en cualquier forma de interacción humana. Expresiones cánticas que ejemplifican esta forma de modelo cognitivo son:

- "La vida es una falsía; el mundo es ancho y ajeno" (Falsía).

- “Mientras yo hervía el agua, otro tomaba el café" (Un desengaño más).

- "No te fijes en tu hermosura, en esta vida es mentira... tal vez serás una ingrata, tal vez serás una hechicera" (Pajarillo de verdes alas).

* Huaracino; gentilicio de la ciudad de Huaraz - Perú. 
- "Malos amigos yo sé que pronto han de olvidarme, así es la vida / mundo de ingratitudes" (Vida bohemia).

- “Corazón desesperado, disimula tu tristeza, tú bien sabes que en este mundo muchos gozan de tu desgracia/desdicha" (Te espero).

- "Mi vida ya no es vida en medio del valle de falsedades / de injusticias sin nombre (Falsía).

- Fijación en lo negativo, cuando las personas enfatizan solo lo malo que les ha ocurrido, siendo incapaces de encontrar, a pesar de todo, alguna bondad o cualidad, vislumbrando en una "visión de túnel" solo las desventajas y adversidades (Gil'Adí, 2000). Las personas, bajo este modelo, solo resaltan aquello que compatibiliza con sus estados de ánimo y actitudes pesimistas, resistiéndose a descubrir situaciones positivas y de oportunidades. Ejemplos de expresión de este modelo son:

- "Para mí ya no hay consuelo / alivio, para la mujer desgraciada todo pasa, todo sucede" (Malvacina).

- “Basta corazón no llores, tu vida no tiene remedio... tu suerte es caso perdido, corazón" (Basta corazón no llores).

- "Sólo estoy tomando dos cervecitas para olvidarme de esta mala vida" (Mala vida).

- "Quien toma más que yo, pero quien puede tomar" (Quién toma más que yo).

- "De qué te lamentas, por qué me críticas, así borrachita me has conocido" (Borrachita).

- "Yo soy el hombre aborrecido de este lugar, es por eso que yo me alejo" (El aborrecido).

- "El mundo para mí no tiene claridad, la vida para mí todo es fatalidad" (Se va mi amor).

\section{Modelos cognitivos en frecuencia de nivel bajo}

En el nivel de frecuencia baja, se ubican seis modelos cognitivos: anticipación de los resultados, absolutismo del siempre o nunca, miedo a lo desconocido, magnificación o catastrofización, salto a las conclusiones y descalificación de lo positivo, que corresponde al $11 \%$, siendo la conceptualización y ejemplos de algunas de sus expresiones las siguientes:

- Anticipación de los resultados, cuando las personas predicen el resultado o destino final de los acontecimientos. Advierte una vocación por "adivinar el futuro", prejuzgando los resultados en un sentido poco o nada optimista, puesto que en sus representaciones el final de todo es solo negativo. Expresan este modelo cognitivo enunciados como:

- "Esta noche nomás canto y mañana todo el día, pasado se acaba la alegría de mi canto" (Amigo mío). 
- "Cuando yo me vaya vivirás dichosa, pero el quien te quiso seguirá llorando/sufriendo" (Penas y suspiros).

- "Lloraré en silencio, mi amor, hecho pedazos mi corazón al leer tu última carta" (Amor herido).

- "No me quieras tanto, por favor de te lo ruego, sabes que en tu vida siempre seré un martirio" (Amor agonizante).

- Absolutismo del siempre o nunca, son pautas de pensamiento y sentimiento polarizados, donde no caben categorías intermedias, en la frecuencia de los acontecimientos, en una perspectiva de indicio del futuro en que las cosas como siempre lo fueron; seguirán aconteciendo en una continuidad (siempre) o discontinuidad (nunca) de manera absoluta e invariable.

- "Ayer fui dichoso, hoy día muy desgraciado" (Ay, justo cielo).

- "Hay dos caminos, caminos extraños, una a la vida; otra a la muerte" (Caminos extraños).

- "La vida es una sola, morir es una sola vez, pero sufrir, padecer, ese es cada vez nomas" (La vida es una sola).

- “Cerveza, más cerveza estoy tomando yo, helada sin helar, de cualquier etiqueta cerveza debe ser" (Cerveza, más cerveza).

- Miedo a lo desconocido, este caso se presenta cuando las personas piensan, imaginan o sienten que las experiencias nuevas o nunca vividas son inciertas y potencialmente peligrosas y amenazantes, induciéndolos a estados de pasividad, así mismo los lleva por la inercia de los acontecimientos o reacciones ansiosos. En quienes subyace este modelo de raciocinio, se prejuzgan como incapaces de gestionar favorablemente los eventos o situaciones desconocidas, bloqueándose en toda posibilidad de poner a prueba su capacidad creativa en la búsqueda de nuevas opciones. Enunciados cánticos que ponen de manifiesto esta forma de modelo cognitivo son, por ejemplo:

- "Qué será pues mi destino, dónde estará pues mi suerte, en los mares o en los ríos no los quiero detrás de mí" (Mi suerte).

- "Dónde estaré mañana cuando me vaya de aquí, abandonado o perseguido tal vez estaré" (El huerfanito).

- “Mañana me iré no sé si volveré, me voy para olvidarte, no sé si volveré" (Mañana me iré).

- "Hay, como no más supiera el día en que voy a morirme, para no salir de mi tierra y quedarme para siempre" (De jarana en jarana).

- Magnificación o catastrofización, comienza cuando una situación amenazante en la subjetividad de la persona se torna incontrolable, ocasionándole reacciones emocionales desequilibradas en 
proporción a la intensidad del evento activador. Este modelo cognitivo se asocia con el temor de no contar con las habilidades para manejar favorablemente las relaciones interpersonales y tolerar las frustraciones (Gil'Adí, 2000). Cuando se piensa o prejuzga que las consecuencias de los acontecimientos o eventos a afrontar serán horribles e inevitables se pone de manifiesto aquella tendencia a responder desproporcionadamente en relación a la intensidad y magnitud de las dificultad o percance que se afronta. Formas que enuncian este modo de raciocinio son, por ejemplo:

- “Clavaste un hadar en mi pecho, me diste el veneno más amargo, mi vida no tiene sentido, para qué quiero la vida" (Mi dolor).

- "Desde el día que te fuiste, mi vida no tiene calma" (Por tu culpa).

- "Que sufrimiento llevo en mi vida, como castigo llevo cadenas; estas cadenas me pesan mucho, están llagando mis pobres manos" (Para qué quiero la vida).

- "Basta corazón no llores, tu vida no tiene remedio" (Basta corazón no llores).

- "Desde que en mis sueños te vi, que suplicio tan amargo es vivir sufriendo, paso mis noches en vela contemplando una visión" (Inspira mi alma).

- Salto a las conclusiones, es una forma de distorsión cognitiva que pone de manifiesta la tendencia en algunas personas a prejuzgar o sacar conclusiones de los hechos en términos negativos sin contar con los elementos suficientes, antes que estos se den. Se torna en una predisposición negativa para emprender acciones de afronte ante las dificultades. Según Burns (2006) en las personas se pone de manifiesto a través de dos supuestos: cuando se da por hecho que las demás personas lo están juzgando (lectura del pensamiento) y cuando se autoafirma que le ocurrirán cosas negativas (adivinación del porvenir). Expresiones, por ejemplo, que ilustran esta forma de raciocinio son:

- "A la mujer desgraciada todo le pasa, todo le sucede" (Malvacina).

- "Otra copa más porque ya no volverás. Yo lloraré, yo sufriré hasta que vuelva mi dulce amor" (Copas de amor).

- Malos amigos yo sé que pronto han de olvidarme, así es el mundo de ingratitudes. (Vida bohemia).

- "Si yo me voy, tú te quedas, sufrirás en este mundo, andarás llorando buscando un consuelo, andarás sufriendo buscando un cariño" (Para qué quiero la vida).

- Descalificación de lo positivo, es la predisposición casi automatizada para subvalorar y desmerecer la propia condición, autovalorándose como poco importantes e intrascendentes en sus buenas acciones. Quienes son influenciados por este argumento tendrán dificultad para sentirse satisfechos por sus 
Modelos cognitivos en las representaciones sociales para la baja autoestima y la ingesta de alcohol en canciones de la sierra peruana

logros, siendo predominantes, por lo general, sus actitudes y estados de ánimo pesimistas o de resistencia a reconocer bondades, cualidades o gratitud en la vida. Expresiones que ejemplifican esta forma de cognición son:

- "Mi vida ya no es vida" (Falsía).

- "Si de mi pecho pudiera arrancarlo mi corazón, ya no anduviera buscando lo que no debo conseguirlo" (Inspira mi alma).

- "Madre porque tuviste un hijo(a) tan desdichado" (Te espero).

\section{Discusión}

Los 18 modelos cognitivos identificados, en los contenidos de los cantos analizados, son el argumento conceptual del raciocinio y la percepción de algunos pobladores de la sierra peruana que se identifican con estas canciones y que sustentan las representaciones sociales para una baja autoestima y la ingesta de alcohol. Estas formas de conceptualización al ser colectivizadas y compartidas, se alejan de ser fortaleza en la identidad social y cultural; contrariamente serían debilidades, cuyo impacto e influencias en el desarrollo de las personas, la familia y la sociedad no serían favorables. En el Perú, no están siendo abordados de forma coherente por los sistemas educativos formal e informal, las políticas públicas de salud, comunicaciones, desarrollo humano y social.

Los contenidos expresos en las canciones, alusivas a la baja autoestima y la ingesta de alcohol, como formas de expresión socio culturales de los pueblos de la sierra peruana, permiten identificar una pluralidad de expresiones, sean en denotaciones, simbolizaciones, analogías, metonimias, e incluso en alusiones directas, modelos cognitivos que dan a entender una condición de representación de sí precarias y pobre valía personal, marcadas por la desesperanza y el fatalismo, minusvalía y resignación al sufrimiento que, no reflejan fortaleza y disponibilidad socio emocional y anímica constructiva, sino por el contrario, fracasos, frustraciones y desengaños, preponderantemente en la vida amorosa y en la relación de pareja que los aproxima a un estado de miseria humana y espiritual, así mismo al ser difundidas directa o indirectamente, hacen apología a formas de vida y comportamientos de riesgo; por lo tanto, es necesario que se propongan estrategias de intervención educativa, capaces de contribuir a la formación de una cultura saludable, pacífica, solidaria y de convivencia armoniosa como base para el desarrollo integral de los pueblos. 
En este contexto, Colomo (2013) en el análisis pedagógico de los valores presente en las canciones, advierte que estas son importantes elementos culturales creadas por la acción humana y son parte esencial de la vida de las personas que influyen en los estados de ánimo y representan un signo de su identidad, llegando a ser un elemento mediador en las relaciones sociales.

Igualmente, en esta mirada, Rojas (2013) reconoce que el Análisis Crítico del Discurso (ACD) de los mensajes de las canciones de la cotidianidad es una herramienta para analizar formas de transmisión de ideologías, cuya difusión por los medios de comunicación, llegan al inconsciente colectivo de sus audiencias por identificarse con las vivencias de los personajes presentes en el discurso lirico, como también Rodríguez y Uriol (2018) lo plantean en el libro Canta, canta que algo queda.

Desde los postulados del paradigma cognitivo conductual propuestos por Ellis y Dryden (1989) estas serían formas de "irracionalidades" o "distorsiones cognitivas" que sustentan y refuerzan las tendencias a la ingesta de alcohol y a una subjetividad de pobre aprecio personal o baja autoestima, que se estarían exteriorizando en los "debo", "tengo que", "no debiera", etc. cual obligaciones absolutas, dan lugar a "tremendismos", ya sea a magnificaciones o dramatizaciones, o los "no puedo soportar" y la "condena" al sufrimiento y desconsuelo, cuya activación y vigencia predisponen a padecimientos extremos en un nivel patológico como la ansiedad, depresión, alcoholismo e incluso el suicidio.

Los análisis económico-sociales estandarizan a muchos pueblos de la sierra peruana como "Los más pobres del Perú", apreciación no muy lejana de la realidad frente al cual cabe la interrogante, ¿Estos modelos cognitivos, como parte de la subjetividad, expresan fortaleza o debilidad?, es así que, consideramos que las políticas públicas de salud y desarrollo humano, deben advertir la condición de expresiones de riesgo que revelan las canciones populares que le cantan al licor y la subvaloración personal; frente al cual es necesario desarrollar acciones preventivas que favorezcan una actitud más saludable y resiliente; que inspiren a enfrentar y superar las adversidades.

Las expresiones canticas y musicales tienen un gran valor en la formación de la conciencia colectiva por ser un lenguaje que propicia la evocación, fortalecimiento, transformación de emociones y ayuda a los grupos o comunidades a mantenerse unidos por vínculos desarrollados a partir de las vivencias (Pardo, 2018). Al respecto, Hurtado (1995) encuentra cómo a través de las canciones se van transmitiendo ciertos valores de la mentalidad andina y popular, como la solidaridad y la búsqueda de un nuevo sistema social más justo. Sin embargo algunos músicos y canta autores están distantes de ser agentes sociales de la educación y referentes constructivos ante la comunidad, en la medida que, en un sentido de apología, difunden y otorgan supuestas cualidades y bondades al licor como el remedio de las penas y sufrimientos, desvirtuando su rol de informar, entretener, orientar y educar, ya que contrariamente estarían 
cumpliendo ante sus audiencias un rol deseducador en la formación de valores positivos, la ética, la moral, los derechos, los deberes, las responsabilidades y todo una gama de comportamientos saludables. Del mismo modo, los medios de comunicación, como recursos importantes en la formación de conciencias y reguladores de conductas, no siempre cautelan la difusión de temas alusivos a la ingesta de alcohol y la baja autoestima o subvaloración personal.

Las ciencias sociales, de la educación y de la salud, no deben soslayar el rol del arte, como el canto, en relación a los fenómenos de la cognición social, y dentro de ellos, en particular, aquellas representaciones o manifestaciones sociales que inducen a la distorsión de la subjetividad e identidad de los pueblos en deterioro de su desarrollo, como sucede en los temas alusivos a la baja autoestima y la ingesta de alcohol.

\section{Conclusión}

Aquellas expresiones canticas de la serranía peruana, cuyos mensajes y contenidos aluden a la baja autoestima, a la ingesta de alcohol o ambas, en mayoría proponen dos o más modelos cognitivos que marcan las orientaciones y reacciones conductuales-emocionales que configuran los escenarios psicosociales en la que se desenvuelven las poblaciones de esta gran región. Desde la perspectiva del análisis cognitivo conductual se registraron 18 modelos cognitivos como base y fundamento de las representaciones sociales para la baja autoestima y la ingesta de alcohol que, de acuerdo a la jerarquía en predominio son: culpar y evadir responsabilidad, inutilidad, impotencia, fragilidad y desamparo, pensamientos y/o sentimientos dicotómicos, esperanza en lo extrahumano, victimización, autoculpa y merecimiento, absolutismo del todo o nada, evocación del pasado, evasión, abandono e ideación suicida, necesidad absoluta de afecto y compañía, susceptibilidad a la estafa y la traición, fijación en lo negativo, anticipación de los resultados, absolutismo del siempre o nunca, miedo a lo desconocido, magnificación o catastrofización, salto a las conclusiones, y descalificación de lo positivo.

La demanda imperiosa de afecto y compañía es el modelo cognitivo presente en el $8 \%$ del cancionero de la sierra peruana que definen una disposición de intolerancia a la experiencia de vivir sin la compañía del ser amado; bajo el concepto de este, es la condición absoluta para el bienestar y una existencia productiva; caso contario, inexorablemente, conllevará a convertir a las personas en seres inútiles, inservibles, desamparadas e intrascendentes.

Un 59 \% de las canciones de la sierra peruana, que aluden a una baja autoestima y la ingesta de alcohol, en un sentido implícito o explicito, revelan modelos cognitivos que connotan elogio o insinuación encubierta o directa al consumo de alcohol; en tanto, son conceptualizadas y racionalizadas como elementos para mitigar las penas y sufrimientos, lo cual, desde una mirada psicosocial y de promoción de 
la salud, equivaldría a una forma de fomento de estilos de vida y comportamientos de riesgo para el desarrollo humano, el bienestar personal, familiar y social.

Los medios de comunicación, en sus diferentes formas, al hacer la difusión musical sea en actos o espacios públicos, también son elementos importantes de educación informal, debido a que no siempre están asumiendo la responsabilidad de contribuir a la formación de conciencias y la regulación de conductas ya que no cuidan la difusión de temas cánticos que insinúan mensajes concernientes a la baja autoestima y la ingesta de alcohol; estando, en consecuencia promoviendo la irresponsabilidad, la pobre autoestima o la intrascendencia en la existencia humana, en un claro proceso de deseducación.

\section{Referencias}

Álvarez, J. (2003). Cómo hacer investigación cualitativa: Fundamentos y Metodología. Paidós.

Arráez, M., Calles, J. y Moreno de Tovar, L. (2006). La Hermenéutica: una actividad interpretativa. Sapiens. Revista Universitaria de Investigación. 7(2), 171-181.

https://www.redalyc.org/articulo.oa?id=41070212

Cabrera, R. (2012). El canto como herramienta terapéutica para mejorar la salud emocional de la mujer. [Tesis de pregrado, Universidad de San Carlos de Guatemala]. Repositorio institucional USAC. http://www.repositorio.usac.edu.gt/10629/

Ministerio de Educación y Consejo Nacional de Educación (2007). Proyecto Educativo Nacional al 2021. http://www.minedu.gob.pe/Delnteres/xtras/PEN-2021.pdf

Colomo, E. (2013). Análisis pedagógico de los valores presente en las letras de las canciones. [Tesis doctoral, Universidad de Málaga]. Repositorio Institucional UMA. https://riuma.uma.es/xmlui/handle/10630/6865

Ellis, A. y Dryden, W. (1989). La práctica de la Terapia Racional Emotiva (RET). Desclée de Brouwer.

Gil’Adí, D. (2000). Inteligencia emocional en práctica. McGraw-Hill Interamericana.

Graham, F. y Welch, G. (2007, 6 de febrero). El canto como un modo de comunicación [conferencia] Key-note for 4th Annual Meeting of SACCoM, Tucumán, Argentina. http://saccom.org.ar/v2016/sites/default/files/Welch\%20El\%20canto\%20como\%20un\%20modo \%20de\%20comunicaci\%C3\%B3n.pdf 
Modelos cognitivos en las representaciones sociales para la baja autoestima y la ingesta de alcohol en canciones de la sierra peruana

Hernández, R. y Mendoza, C. (2018). Metodología de la investigación: Las rutas cuantiaba, cualitativa y mixta. McGraw-Hill Interamericana.

Hurtado, W. (1995). Chicha Peruana. ECO.

Jodelet, D. (1993). La representación social: Fenómeno, concepto y teoría. En S. Moscovici (Ed.), Psicología social (pp. 469-494). Paidós.

Lara, E. (2004). Teoría de las representaciones sociales: Sobre la lírica de los Narcocorridos. Nómadas. Revista Crítica de Ciencias Sociales y Jurídicas, (9), 0. https://www.redalyc.org/pdf/181/18100913.pdf

Ministerio de Educación y Consejo Nacional de Educación (2007). Proyecto Educativo Nacional al 2021. http://www.minedu.gob.pe/Delnteres/xtras/PEN-2021.pdf

Montoya, L. (1987). Canción quechua, historia y región en las provincias altas del sur Andino. [Tesis doctoral inédita]. Universidad Nacional Mayor de San Marcos.

Pardo, M. (2018). Develándome, el arte del canto como mediador del proceso transformador. [Tesis de especialización, Universidad Distrital Francisco José de Caldas].

Repositorio Institucional UDFJC.

https://repository.udistrital.edu.co/bitstream/handle/11349/14903/PardoRuizMar\%C3\%ADaCri stina2018.pdf?sequence $=1$

Perú 21. (2017, agosto 31). ¿Sabes cuánto invierte el Perú en educación? El BID nos brinda algunas cifras. Perú 21. https://peru21.pe/peru/invierte-peru-educacion-373881-noticia/?ref=signwall

Rodríguez, F. (2020). Psicología de los incomprendidos. Editorial San Marcos.

Rodríguez, F. y Uriol, A. (2018). iCanta, canta, que algo queda! Lectura Viva Ediciones.

Rojas, L. (2013). Análisis discursivo de la canción de la cotidianidad: "soy muchacho provinciano".

Escritura y Pensamiento, 16 (33), 25-36. https://doi.org/10.15381/escrypensam.v16i33.8187

Stein, S. (1982). El vals criollo y los valores de la clase trabajadora en Lima de comienzos del siglo XX. Serie Socialismo y Participación, (17), 43-49.

Tamayo y Tamayo, M. (2009). El proceso de la investigación científica. Limusa.

Zapata, S. (1968). Psicoanálisis del vals peruano. Revista de ciencias psicológicas y Neurológicas, 5, 561. 


\section{Contribución de los autores}

APUA: Conceptualización, metodología, investigación, validación, redacción: borrador original.

FFRC: Conceptualización, analisis formal, metodología, investigación, redacción: revisión y edición.

\section{Fuentes de financiamiento}

La investigación fue realizada con recursos propios.

\section{Conflictos de interés}

No presenta conflicto de intereses.

\section{Correspondencia}

antonieta.uriol@unh.edu.edu 